\title{
Investigation of Iron(III)-Release in the Pore Water of Natural Sands by NMR Relaxometry
}

\author{
Ivonne Mitreiter* $^{* 1,2}$, Sascha E. Oswald ${ }^{2,3}$ and Frank Stallmach ${ }^{1}$ \\ ${ }^{1}$ University of Leipzig, Department of Interface Physics, Linnéstr. 5, 04103 Leipzig, Germany \\ ${ }^{2}$ UFZ-Helmholtz Centre for Environmental Research, Department of Hydrogeology, Permoserstr. 15, 04318 Leipzig, \\ Germany \\ ${ }^{3}$ University of Potsdam, Institute of Earth and Environmental Science, Karl-Liebknecht-Straße 24-25, 14476 Potsdam, \\ Germany
}

\begin{abstract}
Proton nuclear magnetic resonance (NMR) relaxometry offers a non-invasive and non-destructive measurement method to observe and to visualise changes in the iron(III)-ion concentration in aqueous solutions. This is possible due to its paramagnetic influence on the relaxation times. In the context of mineral dissolution processes in natural sediments, the effect of the presence of dissolved iron(III) on the NMR relaxation times of the pore water was investigated. The decrease in the relaxation times $T_{1}$ and $T_{2}$ corresponding to an increase in the dissolved iron(III) concentration was quantified. This relation was used to monitor relative changes in the concentration of dissolved iron(III)-ions in natural sands.

Experiments were conducted to calibrate the iron(III) concentration from the measured relaxation times. These were done in bulk water as well as in iron(III)-mineral bearing sands to take the effect of surface relaxation into account. It was shown that for relatively coarse-grained sand fractions the effect of iron(III)-ions in solution dominates. This allows the determination of the dissolved iron(III) concentration in natural sands by NMR. The method also enables us to capture the changes in the iron(III) concentration with high temporal resolution. This was demonstrated in column experiments, in which an acid (hydrochloric or sulphuric acid) was applied from the top on the sands to dissolve the mineralogical bound iron(III) and were the dissolution of iron(III) can be captured with sufficient temporal resolution.
\end{abstract}

Keywords: Paramagnetic ion, iron(III), relaxation, mineral dissolution.

\section{INTRODUCTION}

Acid mine drainage is globally a major environmental issue. The groundwater is often heavily polluted near mines of sulphide minerals. This is due to the continuously release of low $\mathrm{pH}$ and heavy-metal loaded water from the mines draining into groundwater [1]. The oxidation of pyrite and other metal-sulphide minerals by oxygen plays a key-role in acid mine drainage. It acts as a source of sulphate and iron $(\mathrm{Fe})$ in groundwater, and of heavy metals in general in the environment [1]. Dissolved iron is not detrimental to human health, but high concentrations have a negative impact on the usefulness of the water. It can cause clogging of well-screen openings and pumps and has an unpleasant metallic taste.

Iron exists either in a ferrous $\mathrm{Fe}^{2+}$ or ferric $\mathrm{Fe}^{3+}$ state. In which form iron is dissolved in water depends on the amount of oxygen and upon its degree of acidity. $\mathrm{Fe}^{2+}$ is oxidised to $\mathrm{Fe}^{3+}$ in contact with oxygen or by the action of iron related bacteria. $\mathrm{Fe}^{2+}$-ion is very soluble, but $\mathrm{Fe}^{3+}$-ion is only soluble at low $\mathrm{pH}$ values in water. Iron is a major component in acid mine waters. Precise measurements are important in order to understand the processes taking place regarding the dissolution of $\mathrm{Fe}^{3+}$-ions.

*Address correspondence to this author at the UFZ-Helmholtz Centre for Environmental Research, Department of Hydrogeology, Permoserstr. 15, 04318 Leipzig, Germany; Tel: +493412351253; Fax: +493412351837; E-mail: ivonne.mitreiter@ufz.de
In most present analytical methods [2], $\mathrm{Fe}^{3+}$-ion is determined by computing the difference between the total dissolved $\mathrm{Fe}$ and the dissolved $\mathrm{Fe}^{2+}$, i.e. $\mathrm{Fe}^{3+}$-ion concentrations are determined in an indirect way. The determination of $\mathrm{Fe}^{3+}$-ion concentration in water is based on the determination of $\mathrm{Fe}^{2+}$-ion concentrations, followed by a separate determination of the total dissolved $\mathrm{Fe}$ concentration after the reduction of $\mathrm{Fe}^{2+}$. The difference between the concentrations of total dissolved $\mathrm{Fe}$ and $\mathrm{Fe}^{2+}$ is taken as the $\mathrm{Fe}^{3+}$-ion concentration. One major problem with this approach is the overestimation of $\mathrm{Fe}^{3+}$-ion concentration at high $\mathrm{Fe}^{2+}$-ion concentrations in the analyzed sample, where the difference between total dissolved $\mathrm{Fe}$ and $\mathrm{Fe}^{2+}$ is comparable to the error of the determination.

In this study we applied nuclear magnetic resonance (NMR) relaxometry measurements as a method for the direct determination of dissolved $\mathrm{Fe}^{3+}$-ion concentrations. This is possible due to the paramagnetic properties of $\mathrm{Fe}^{3+}$-ions influencing the NMR measurements. Mostly, paramagnetic ions (e.g. $\mathrm{Fe}^{3+}, \mathrm{Mn}^{2+}, \mathrm{Ni}^{2+}$ and $\mathrm{Cu}^{2+}$ ) are seen as a complicating factor in the NMR interpretation due to their significant influence on the relaxation times. Previous studies concentrate on the effects of solid paramagnetic species and paramagnetic ions adsorbed to the solid phases [3, 4]. In many natural samples the iron concentrations are high enough to have a significant influence on the surface relaxivity. Bryar et al. [5] point out to be careful with the interpretation of 
pore size distributions between samples unless the iron concentration is observed to be the same. Bryar et al. [5, 6] showed that the relaxation rates of $\mathrm{Fe}^{3+}$-solutions depend linearly on the $\mathrm{Fe}^{3+}$-ion concentration.

Present NMR techniques allow a wide range of applications. They can be used to provide information on the temporal and spatial distribution of water and dissolved ions, on flow and transport processes [7-10]. NMR has also been used to investigate several microbial processes and biofilm properties via relaxation time differences $[11,12]$. NMR applications are used to characterize sediments [13-16] and in well logging [17].

The aim of this study is to apply NMR relaxometry measurements to determine directly the dissolved $\mathrm{Fe}^{3+}$-ion concentrations in the sediment pore water. By measuring the relaxation times of water saturated sediment samples and taking surface relaxation at the pore matrix interface into account, the $\mathrm{Fe}^{3+}$-ion concentration in the pore water solution can be calculated. Additionally, column experiments are performed which show that this approach allows to monitor the time dependence of the dissolution of naturally occurring $\mathrm{Fe}^{3+}$ in minerals. Thus, NMR relaxometry is used to gain non-invasive and non-destructive insights into such processes with high temporal resolution.

\section{BACKGROUND AND THEORY}

\section{Relaxation in Solution and in Porous Media}

The relaxation times of water decrease with increasing viscosity and increasing amount of solvents, respectively, and especially with increasing amount of dissolved paramagnetic species, such as dissolved oxygen or $\mathrm{Fe}^{3+}$-ions. The theoretical background to these relaxation processes in liquids was founded by the Bloembergen-Purcell-Pound (BPP) theory [18]. Small concentrations of dissolved paramagnetic metal ions cause huge decrease of the relaxation times. Hence, the bulk relaxation rate is a sum of the paramagnetic and diamagnetic contributions and consequently proportional to paramagnetic ion concentration as well as the number of water molecules in the hydration sphere of an ion $[19,20]$. The relaxation rates in bulk water $\left(1 / \mathrm{T}_{1 \mathrm{~b}}, 1 / \mathrm{T}_{2 \mathrm{~b}}\right)$ with dissolved paramagnetic ions depend linearly on the ionconcentration c:

$$
1 / T_{1 b, 2 b}=1 / T_{1 b 0}, 2 b_{0}+R_{1,2} * c
$$

where $T_{1 b 0}$ and $T_{2 b 0}$ are the relaxation times of paramagnetic ion-free water. The relaxivities $\mathrm{R}_{1,2}$ of the paramagnetic ion depends on the electron spin state of the ion and the magnetic field strength at which the measurement is performed.

The relaxation rate of water in a porous material is larger than in bulk water because of additional mechanisms, which enhance the relaxation. The restriction of the water mole- cules at the solid pore walls of the pore space and the content of paramagnetic ions at the surface of these particles cause an additional surface relaxation mechanism [21]. So the longitudinal and transverse relaxation rates can be described as a sum of relaxation rates:

$$
1 / T 1,2=1 / T 1 b, 2 b+1 / T 1 s, 2 s
$$

where $T_{1,2 \mathrm{~b}}$ and $\mathrm{T}_{1,2 \mathrm{~s}}$ are the bulk and surface relaxation times. In the fast diffusion regime (meaning that all protons travel to and relax at the pore surfaces in the time interval of the NMR experiment) the surface relaxation time depends on the volume-to-surface ratio V/S of the pores and is given by

$T 2 s=1 / \rho_{s} * V / S$

where $\rho_{\mathrm{s}}$ is the surface relaxivity. It is influenced by the interaction of the pore fluid molecules with the internal pore surface and has been found to increase with the concentration of minerals containing paramagnetic ions on the pore surface [22].

\section{NMR Pulse Sequences}

By applying a series of RF pulses, the total nuclear magnetization of the ${ }^{1} \mathrm{H}$ nuclei of the (pore) water (i.e. the spin system) can be manipulated. Such pulse sequences can be used to determine the relaxation times. The following sequences have been implemented in the work reported in this paper: inversion recovery (IR) sequence [23] and the CarrPurcell-Meiboom-Gill (CPMG) echo train [24, 25]. The IR sequence was used for $\mathrm{T}_{1}$ measurements. In this sequence an inverting $\pi$ RF pulse is followed, after the time interval t', by a $\pi / 2$ pulse (Fig. 1a). During the time interval $t$ ', the magnetization is subjected to longitudinal $\left(\mathrm{T}_{1}\right)$ relaxation only. The CPMG sequence was used to obtain $\mathrm{T}_{2}$. After an initial excitation of the magnetization by a $\pi / 2 \mathrm{RF}$ pulse a spin echo train is generated by $\pi$ RF pulses (Fig. 1b).

\section{Paramagnetic Iron(III)-Ions}

Paramagnetic ions are found to have a strong influence on the NMR relaxation times. A paramagnetic species commonly found in groundwater, soils and sediments is $\mathrm{Fe}^{3+}$. $\mathrm{Fe}^{3+}$-ions have the electron spin quantum number $S=2.5$. Compared to this, $\mathrm{Fe}^{2+}$-ions have a lower electron spin values of $\leq 2$. Due to this lower electron spin quantum number $\mathrm{Fe}^{2+}$-ions have a smaller effect on the relaxation times. Hence NMR measurements allow the observation of redox reactions using the $\mathrm{Fe}^{3+}-\mathrm{Fe}^{2+}$-redox pair [6]. In another chemical form, i.e. as complexed $\mathrm{Fe}^{2+}$, iron has recently been used to characterize biofilms [26].

The most common iron-oxides are goethite $(\alpha-\mathrm{FeOOH})$, hematite $\left(\alpha-\mathrm{Fe}_{2} \mathrm{O}_{3}\right)$, lepidocrocite $(\gamma-\mathrm{FeOOH})$, ferrihydrite $\left(\mathrm{Fe}(\mathrm{OH})_{3} * \mathrm{nH}_{2} \mathrm{O}\right)$ and magnetite $\left(\mathrm{Fe}_{3} \mathrm{O}_{4}\right)$. These iron-oxides

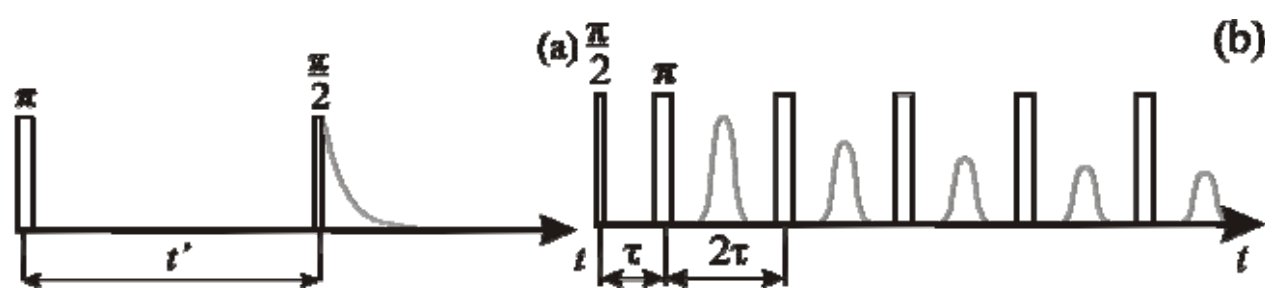

Fig. (1). Pulse sequences used in this study, a) IR sequence to obtain $T_{1}$, b) CPMG for measuring $T_{2}$. 
are pure $\mathrm{Fe}^{3+}$-minerals, with the exception of magnetite which contains both $\mathrm{Fe}^{3+}$ and $\mathrm{Fe}^{2+}$. The concentration of total iron in soils and sediments is normally around $0.2-5 \%$. For porous media Foley et al. [3] and Bryar et al. [5] have shown that the surface relaxivity $\rho_{\mathrm{s}}$ and with this the surface relaxation rate $1 / \mathrm{T}_{1,2 \mathrm{~s}}$ is linearly proportional to the concentration of paramagnetic ion containing minerals on the pore surface.

In groundwater and soil water, iron exists either in a ferrous $\mathrm{Fe}^{2+}$ or ferric $\mathrm{Fe}^{3+}$ state. Which form iron takes, is controlled by $\mathrm{pH}$ and redox potential. Ferric iron is relatively insoluble in water. Only at $\mathrm{pH}$ values below 3.0 it is expected to appear in solution, e.g. in acidic water from metal mines and acidic forests soils. The relaxation rates of $\mathrm{Fe}^{3+}$ solutions are sensitive to $\mathrm{pH}$-dependent speciation of the ion [5]. In aqueous solution at $\mathrm{pH} 1.0, \mathrm{Fe}^{3+}$ is present mostly complexed by six molecules of water, $\left[\mathrm{Fe}\left(\mathrm{H}_{2} \mathrm{O}\right)_{6}\right]^{3+}$, but at $\mathrm{pH} 3.0$ hydrolysis reactions change the iron to a mixture of $\left[\mathrm{Fe}\left(\mathrm{H}_{2} \mathrm{O}\right)_{6}\right]^{3+},\left[\mathrm{Fe}\left(\mathrm{H}_{2} \mathrm{O}\right)_{5} \mathrm{OH}\right]^{2+}$ and $\left[\mathrm{Fe}\left(\mathrm{H}_{2} \mathrm{O}\right)_{4}(\mathrm{OH})_{2}\right]^{+}[5]$. The number of exchangeable water molecules in the hydration sphere decreases as $\mathrm{pH}$ increases [5].

With increasing $\mathrm{pH}$, the $\mathrm{Fe}^{3+}$ adsorbs to the solid surfaces of surrounding porous media. Bryar et al. [5] showed that at pH 3.0 roughly $20 \%$ of $\mathrm{Fe}^{3+}$ can be adsorbed to surfaces. The presence of adsorbed $\mathrm{Fe}^{3+}$ ions on the surface as well as $\mathrm{Fe}^{3+}$-bearing solid phases present as surface coatings or as separate mineral grains also significantly increase the surface relaxation.

\section{MATERIALS AND METHODS}

\section{Materials and NMR Sample Preparation}

The sand samples investigated originate from a sand deposit about $10 \mathrm{~km}$ west of Leipzig, Germany. It was formed as a terminal moraine during the ice ages of the middle Pleistocene. Previous analyzes of sand samples from the same location [16] showed that the sand consists of quartz and feldspar and that the averaged elemental composition of the grain surfaces contains iron $\left(\mathrm{Al}_{1} \mathrm{Si}_{2.3} \mathrm{O}_{9.3} \mathrm{Fe}_{0.4}(\mathrm{Mg}, \mathrm{Ca})_{0.2}\right.$ $\left.(\mathrm{Na}, \mathrm{K})_{0.1}\right)$. In the lab the sand was air dried and sieved yielding 5 fractions with grain diameters in the following ranges: $63 \mu \mathrm{m}-125 \mu \mathrm{m}-200 \mu \mathrm{m}-500 \mu \mathrm{m}-800 \mu \mathrm{m}-1 \mathrm{~mm}$.

The fluids used in this study were distilled water and solutions of $\mathrm{Fe}^{3+}$. The iron solutions were prepared in distilled water using ferric chloride $\left(\mathrm{FeCl}_{3} * 6 \mathrm{H}_{2} \mathrm{O}\right)$ with the $\mathrm{pH}$ adjusted at $\mathrm{pH} 1.0$ using hydrochloric acid. Although the $\mathrm{pH}$ of pore fluids in natural settings will not often be as low as those used in this experiment, we used solutions with high acidity to ensure a complete dissolution of $\mathrm{Fe}^{3+}$-ions, which facilitates the interpretation of the results. Measurements of the relaxation time of the bulk fluids $\left(T_{1,2 b}\right)$ were made using approximately $2 \mathrm{ml}$ of the equilibrated fluid in an NMR tube.

The water-saturated sands were prepared by mixing $6 \mathrm{~g}$ sand with $1.5 \mathrm{ml}$ distilled water in acid-washed glass tubes. Then acid (hydrochloric acid, sulphuric acid) was added from the top. For observing the time depended reactions with acid the measurements started right after sample preparation. All other sand samples prepared with an acid were left for seven days to insure the completeness of the reaction. Before NMR data were collected, excess fluid was removed from the surface of the sample. NMR data for each sample were collected at room temperature $\left(22^{\circ} \mathrm{C}\right)$. Evaporative losses of water from the sample during data collection were avoided.

\section{NMR Experiments}

The NMR relaxometry measurements were performed using a PC-controlled NMR console MARAN DRX (Resonance Instruments, GB). The home-built permanent magnet permits a magnetic flux density of $\mathrm{B}_{0}=0.2 \mathrm{~T}$, corresponding to a ${ }^{1} \mathrm{H}$ resonance frequency of $9.1 \mathrm{MHz}$. The NMR samples have $20 \mathrm{~mm}$ outer diameter and the same filling height. In the pulse sequences the length of the $\pi / 2$ and $\pi \mathrm{rf}$ pulses was 7 and $14 \mu \mathrm{s}$. The $\mathrm{T}_{1}$-weighted time interval t' of the IR pulse sequence was varied from 5 to $5,000 \mathrm{~ms}$. In order to provide a sufficiently high signal-to-noise ratio, a minimum of 16 scans were acquired for each t'-value. The inter-echo time $\tau$ in the CPMG pulse sequence was varied from 100 to $400 \mu \mathrm{s}$. A repetition delay time of $\mathrm{RD}=5 \mathrm{~s}$ was sufficient to allow the nuclear spins to relax to equilibrium after each individual scan.

\section{RESULTS AND DISCUSSION}

\section{$\mathrm{Fe}^{3+}$-Ions in Solution}

We measured the longitudinal and transverse relaxation rates $\left(\mathrm{T}_{1}^{-1}\right.$ and $\left.\mathrm{T}_{2}^{-1}\right)$ of solutions containing $\mathrm{Fe}^{3+}$ - ions with concentrations ranging from $0 \mathrm{~g}^{-1}$ up to $5 \mathrm{~g} \mathrm{l}^{-1}$ at a $\mathrm{pH}$ of 1.0. Both measured relaxation rates are shown as a function of the concentration of dissolved $\mathrm{Fe}^{3+}$-ions in Fig. (2). The relaxation rates increase linearly with increasing $\mathrm{Fe}^{3+}$-ion concentration, which corresponds well with the expectation according to the BBP theory. Linear fits for both relaxation rates were generated and are presented in Fig. (2) as solid $\left(\mathrm{T}_{1}^{-1}\right)$ and dashed lines $\left(\mathrm{T}_{2}^{-1}\right)$, respectively.

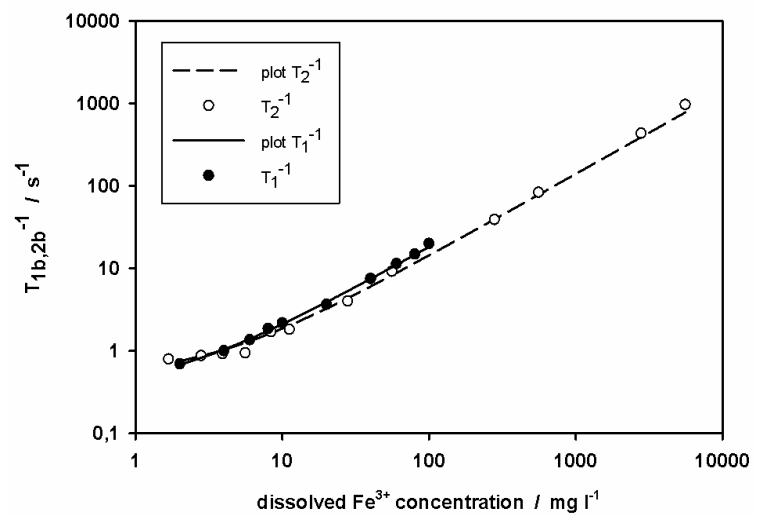

Fig. (2). The dependence of the bulk water relaxation rates $\mathrm{T}_{1 \mathrm{~b}}{ }^{-1}$ and $\mathrm{T}_{2 \mathrm{~b}}{ }^{-1}$ on dissolved $\mathrm{Fe}^{3+}$-ion concentration at $\mathrm{pH} 1.0$ and room temperature $\left(22^{\circ} \mathrm{C}\right)$. The solid line in the graph is the calibration plot for $\mathrm{T}_{1}{ }^{-1}$, the dashed line is the one for $\mathrm{T}_{2}{ }^{-1}$. Please note the logarithmic scale, which contort the linear dependency, especially for $\mathrm{Fe}^{3+}$ ion concentrations below $10 \mathrm{mg} \mathrm{l}^{-1}$.

From the slope data of these calibration plots, using Equation 1, the relaxivities of $\mathrm{Fe}^{3+}$-ions in water, $\mathrm{R}_{1}$ and $\mathrm{R}_{2}$, were determined to be $R_{1}=0.1792 \pm 0,0040 \mathrm{~s}^{-1} \mathrm{mg}^{-1} 1$ and $\mathrm{R}_{2}$ $=0.1393 \pm 0,0018 \mathrm{~s}^{-1} \mathrm{mg}^{-1} 1$ (with correlation coefficients $\mathrm{R}^{2}$ $>0.997)$. 
These results are used to calibrate relaxation rates measured by $\mathrm{NMR}$ to $\mathrm{Fe}^{3+}$-ion concentrations. In the following experiments we measured one of the two relaxation rates and then calculated the $\mathrm{Fe}^{3+}$-ion concentration in solution. This allows us to determine the $\mathrm{Fe}^{3+}$-ion concentration in solution, without the necessity of destroying the sample or use any other analytical tool. Therefore, this technique can be used to capture the temporal progress of such dissolution reactions.

\section{Relaxation Times $\mathbf{T}_{1,2}$ in Water-Saturated Sands}

Internal surfaces of porous media have a significant influence on the relaxation times. To assess this influence for the samples of natural sands the relaxation times of distilled water in five size fractions of the sand were measured. The results are shown as a function of the grain diameter in Fig. (3). Relaxation times in the sands are reduced compared to the relaxation times of bulk water. The smaller the grain sizes the larger is the decrease of the relaxation times. This is due to the interaction of the water ${ }^{1} \mathrm{H}$ nuclei with the surface of the sand grains. This effect on relaxation time is represented by the $\rho_{\mathrm{s}}{ }^{*} \mathrm{~S} / \mathrm{V}$ term in Equation 2.

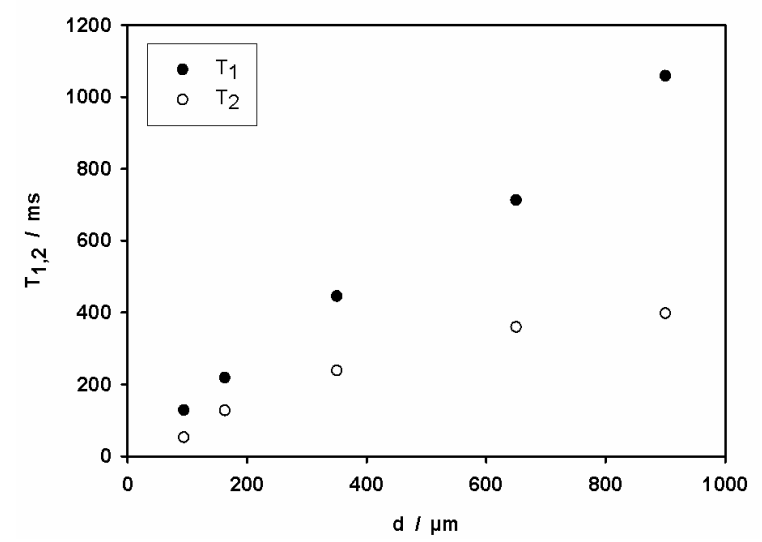

Fig. (3). Relaxation times $T_{1}$ and $T_{2}$ of bulk water for five sand fractions. The diameter $\mathrm{d}$ is the mean value of the particular sand fraction.

For the calculation of the surface relaxivity $\rho_{\mathrm{s}}$ of water in the sands a porosity $\Phi$ of 0.35 is assumed. The $\mathrm{S} / \mathrm{V}$ ratio of a random packing of spherical grains of diameter $\mathrm{d}$ is given as [27].

$S / V=6 *(1 / \Phi-1) * 1 / d$

By substitution Equations 3 and 4 in Equation 2 results

$$
1 / T=1 / T_{b}+\rho_{s} * 6 *(1 / \Phi-1) * 1 / d
$$

With this Equation the surface relaxivity $\rho_{\mathrm{s}}$ of the sands are calculated to be $0.0056 \mathrm{~cm} \mathrm{~s}^{-1}$ for $T_{1}^{-1}$ and $0.0123 \mathrm{~cm} \mathrm{~s}^{-1}$ for $\mathrm{T}_{2}^{-1}$.

\section{Relaxation Times of Water-Saturated Sand with Dis- solved $\mathrm{Fe}^{3+}$-Ions}

By adding an acid to a water-saturated sand sample, the $\mathrm{Fe}^{3+}$-containing minerals dissolve and the $\mathrm{Fe}^{3+}$-ion concentration in solution increases. Fig. (4) shows the longitudinal relaxation time $T_{1}$ for the different sand fractions without acid (from Fig. 3, black dots) and after adding $\mathrm{H}_{2} \mathrm{SO}_{4}$ (empty triangles). The addition of the acid $\left(33 \mu \mathrm{mol} \mathrm{H} \mathrm{H}^{+}\right)$to the sand caused a decrease in the $\mathrm{T}_{1}$ relaxation time corresponding to an increase in the $\mathrm{Fe}^{3+}$-ion concentration in solution. For the two fine-grained fractions just small changes in the relaxation times could be detected because relaxation is fast already without $\mathrm{Fe}^{3+}$-ions. This does not imply that no $\mathrm{Fe}^{3+}$ was dissolved, rather demonstrates the fact that for these fractions the surface relaxation is dominant. The larger the grain size the larger is the relative effect of the dissolved $\mathrm{Fe}^{3+}$-ions on the total relaxation times.

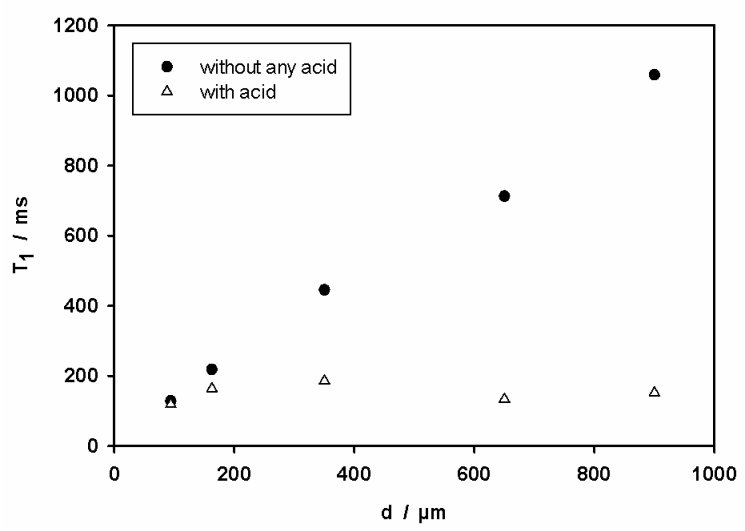

Fig. (4). Relaxation times $T_{1}$ for the 5 sand fractions after adding $\mathrm{H}_{2} \mathrm{SO}_{4}$.

After 7 days time the reaction has presumably ended and the resulting relaxation times $T_{1}$ are in the range from 120 $\mathrm{ms}$ to $180 \mathrm{~ms}$ for the five sand fractions (Fig. 4). Applying Equations 1, 2 and 3, the $\mathrm{Fe}^{3+}$-ion concentration can be estimated using the following Equation

$1 / T_{1}=1 / T_{1 b_{0}}+\rho_{s} * S / V+R_{1} * c$

This corresponds to a $\mathrm{Fe}^{3+}$-ion concentration ranging from $3 \mathrm{mg} \mathrm{l}^{-1}$ for the smallest sand fraction up to $33 \mathrm{mg} \mathrm{l}^{-1}$ for the largest grain sizes, as seen in Fig. (5). This range is due to the varying surface effects in the different sand fractions. The error bars were estimated using the Gaussian error propagation based on the diameter range in each fraction, i.e. the smallest und the largest diameter in each fraction. It is clearly seen that for smaller fraction the error in determining the $\mathrm{Fe}^{3+}$-ion concentration is almost as large as the estimated value. This implies that the estimated $\mathrm{Fe}^{3+}$-ion concentration for the smaller sand fraction is uncertain and therefore, may be misleading. The grain size used in the following experiment is the fraction from 200 to $500 \mu \mathrm{m}$, which is large enough to ensure that the influence of the surface relaxivity on $\mathrm{T}_{1}$ and $\mathrm{T}_{2}$ is low compared to the influence of the $\mathrm{Fe}^{3+}$ ions in solution. Another reason for this choice is the fact that this fraction of grain sizes has the largest percentage in our sand sample and generally speaking, this is one of the most important fractions when considering sand and soil samples.

As a next step column experiments were performed, where different concentrations of hydrochloric acid $(\mathrm{HCl})$ were added from the top to one water-saturated grain size fraction to dissolve different amounts of $\mathrm{Fe}^{3+}$. The added acid concentrations ranged from $4 \mu \mathrm{mol}$ up to $52 \mu \mathrm{mol} \mathrm{H}^{+}$. 


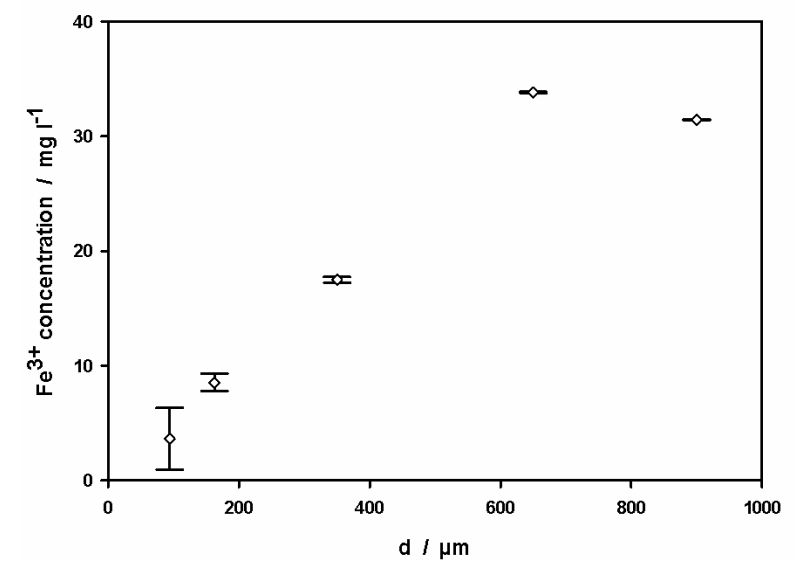

Fig. (5). The estimated $\mathrm{Fe}^{3+}$-ion concentration for each sand fraction with the error bars based on the diameter range for each fraction.

Starting from the smallest concentration, the acid concentration was increased in 6 steps till reaching the largest concentration. To investigate effects on changes of surface relaxivities due to dissolution of mineral phases by increasing acidity the relaxation time distributions were analyzed. To the sand with the highest acid concentration $\left(52 \mu \mathrm{mol} \mathrm{H}^{+}\right)$sodium hydroxide $(\mathrm{NaOH})$ as base was added in surplus. This leads to the almost complete precipitation of the dissolved $\mathrm{Fe}^{3+}$. The corresponding relaxation time distribution is dominated by one peak at short relaxation times. In contrast, the relaxation time distributions before acid addition and after base addition were found to be very similar. Both showed a bimodal distribution with much longer relaxation times than in the state after hydrochloric acid addition and $\mathrm{Fe}^{3+}$ dissolution (data not shown). Although after base addition, the iron precipitates not in the same chemical state and physical form as it previously existed, the initial relaxation time distribution can be reproduced, which implies that the surface relaxivity is not substantially affected by the iron minerals present.

For observing the dissolution of $\mathrm{Fe}^{3+}$-ions with high temporal resolution, the directly measured $\mathrm{T}_{2}$ relaxation time is much better suited than the slower $\mathrm{T}_{1}$ measurement. One $\mathrm{T}_{2}$ measurement by the CPMG-method lasts only a few minutes while a quantitative $T_{1}$ measurement by the IR method requires approximately $15 \mathrm{~min}$ up to about one hour (depending on the required t' intervals to capture the relaxation curve, see Fig. 1). Furthermore, the measurements were performed at a magnetic field of $\mathrm{B}_{0}=0.2 \mathrm{~T}$, so that influences on the $T_{2}$ relaxation time due to internal field gradients can be neglected. Thus, we measured $\mathrm{T}_{2}$ and calculated the $\mathrm{Fe}^{3+}$ ion concentration using the calibration described by the Equation

$c=\left(1 / T_{2}-1 / T 2 b-1 / T 2 s\right) / R 2$

where $1 / T_{2}$ is the measured relaxation rate and the term $\left(1 / T_{2 b}+1 / T_{2 s}\right)$, which describes the total relaxation rate due to bulk and surface relaxation, is determined experimentally before the addition of the acid. $\mathrm{R}_{2}$ is known from the slope of the calibration plot described before (compare Fig. 2). At the beginning, measurements were taken continuously in time intervals of minutes. With time passing, i.e. the reaction slowing down, the time intervals were set larger, up to one hour between two measurements. The duration of the experiment was one day ( 24 hours). The temporal progress can be seen in Fig. (6) for three different acid concentrations. During the first hours a rapid increase in the $\mathrm{Fe}^{3+}$-ion concentration in solution is observed, later the $\mathrm{Fe}^{3+}$-ion concentration converges towards an asymptotic value. These data show that the dissolution of $\mathrm{Fe}^{3+}$-ions from the minerals is a fast process. The controlling mechanism to achieve equilibrium in the sample is the diffusion of $\mathrm{Fe}^{3+}$ - ions as well as $\mathrm{H}^{+}$-ions.

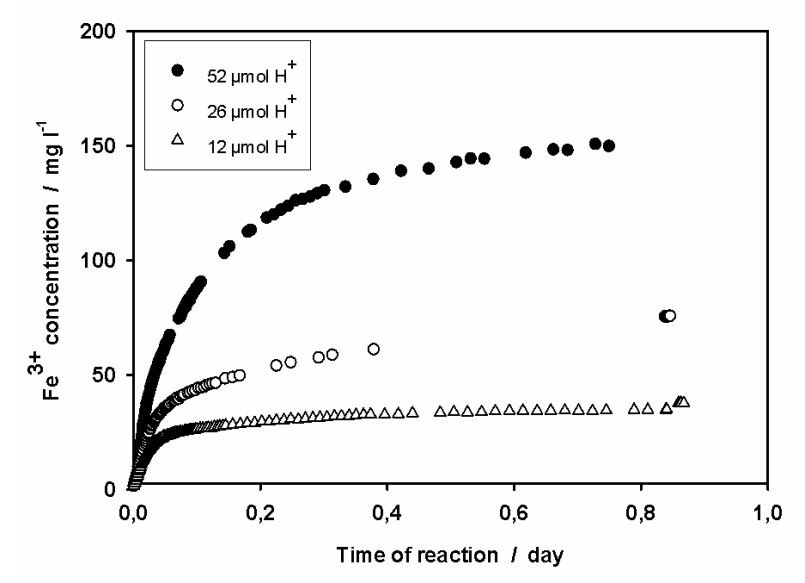

Fig. (6). $\mathrm{Fe}^{3+}$-ion concentration in the $200-500 \mu \mathrm{m}$ sand fraction after adding an acid during the first day of reaction.

\section{SUMMARY AND CONCLUSION}

The paramagnetic behaviour of $\mathrm{Fe}^{3+}$-ions was used in this NMR relaxometry study to monitor temporal changes in $\mathrm{Fe}^{3+}$-ion concentration in aqueous solution. To derive the relation between both relaxation times $\left(T_{1}\right.$ and $\left.T_{2}\right)$ and the $\mathrm{Fe}^{3+}$-ion concentration in solution, different solutions were prepared and the corresponding relaxation times were measured. A linear relationship was found and parameterised. For the subsequent experiments the measured relaxation times could be transformed into $\mathrm{Fe}^{3+}$-ion concentration using the calibration plots. In the next step the influence of the sand grain size on relaxivities was investigated. As it is well known from theory, the smaller the particle size the more dominant is the surface relaxation process. This behaviour was reproduced for four different sand fractions. The conclusions are that a clear separation between both relaxation mechanisms, via $\mathrm{Fe}^{3+}$-ions in solution and via surface relaxation, is not possible for fine-grained sands, where the relaxation times are dominated by the surface relaxation. However, for larger size fraction of natural sand grains, the NMR method was shown to be capable to yield the $\mathrm{Fe}^{3+}$-ion concentration in column experiments, were the increasing dissolved $\mathrm{Fe}^{3+}$ concentrations resulted from the penetration of an acid front through a sand sample. The addition of acid to the sample made $\mathrm{Fe}^{3+}$-ions dissolve from the iron minerals present in the sands. The dissolution process was observed at a high temporal resolution and is characterized by a fast dis- 
solution of $\mathrm{Fe}^{3+}$-ions and diffusion of $\mathrm{H}^{+}$and $\mathrm{Fe}^{3+}$-ions through the pores of the sand.

This quantitative approach offers to monitor changes in dissolved $\mathrm{Fe}^{3+}$-ion concentrations due to changes of acidity in sediments and other release or consumption processes affecting dissolved $\mathrm{Fe}^{3+}$-ions. The experiments proof that the approach is applicable to natural sediments provided the grain size is not smaller than about $100 \mu \mathrm{m}$. Via $\mathrm{T}_{2}$ measurements the temporal resolution is high enough to follow changes in concentration induced by geochemical and also microbial turn-over processes. Doing so, it should be noted that the formation of metal-organic complexes in sedimentand soil-solutions can reduce the relaxivities of $\mathrm{Fe}^{3+}$ as compared to those in model solutions [28]. Besides the dissolution of paramagnetic ions the swelling of soil organic matter and the production and release of extracellular polymeric substances (EPS) by microbes can lead to changes in spin relaxation mechanisms and should be considered [29].

Methodological conclusions of the presented study are that for natural sands of medium and coarse size fractions the dissolution of $\mathrm{Fe}^{3+}$-ions from natural, $\mathrm{Fe}^{3+}$-containing minerals causes a substantial decrease of both, $T_{1}$ and $T_{2}$ relaxation times. Future use of the presented approach could make use of systems with low-field permanent magnets, in our case providing $\mathrm{B}_{0}=0.2 \mathrm{~T}$, which are cost-effective or even mobile. In general, a number of situations can be assessed in terms of changes in dissolved $\mathrm{Fe}^{3+}$, for example (i) rate of acidification and leaching in mine heaps, (ii) the dissolution of $\mathrm{Fe}^{3+}$ in soil induced by organic acids produced by plant roots to improve iron uptake from soil or (iii) iron reduction and re-oxidation during microbial degradation of organic contaminants in aquifers and $\mathrm{Fe}^{3+}$ precipitation from solution in general.

\section{ACKNOWLEDGEMENTS}

Financial support by the DFG (Germany) and the NWO (The Netherlands) via their joint International Research Training Group "Diffusion in Porous Materials" is gratefully acknowledged. The authors thank Dr. J. Kolander (University of Leipzig, Germany) for his assistance with NMR measurements.

\section{REFERENCES}

[1] Appelo CAJ, Postma D. Geochemistry, groundwater and pollution. $2^{\text {nd }}$ ed. A.A. Leiden: Balkema Publishers 2005.

[2] Skoog DA, Leary JJ. Instrumentelle analytik: grundlagen-geräteanwendungen. German ed. Berlin: Springer 1996.

[3] Foley I, Farooqui SA, Kleinberg RL. Effects of paramagnetic ions on NMR relaxation of fluids at solid surfaces. J Magn Reson Ser A 1996; 123: 95-104.

[4] Kenyon WE, Kolleeny JA. NMR surface relaxivity of calcite with adsorbed $\mathrm{Mn}^{2+}$. J Colloid Interface Sci 1995; 170: 502-14.

[5] Bryar TR, Daughney CJ, Knight RJ. Paramagnetic effects of iron(III) species on nuclear magnetic relaxation of fluid protons in porous media. J Magn Reson 2000; 142: 74-85.
[6] Bryar TR, Knight RJ. Sensitivity of nuclear magnetic resonance measurements to changing redox conditions. Geophys Res Lett 2002; 29(24): 2197

[7] Van As H, van Dusschoten D. NMR methods for imaging of transport processes in micro-porous systems. Geoderma 1997; 80: 389403.

[8] Nestle N, Wunderlich A, Niessner R, Baumann T. Spatial and temporal observations of adsorption and remobilization of heavy metal ions in a sandy aquifer matrix using magnetic resonance imaging. Environ Sci Technol 2003; 37(17): 3972-77.

[9] Moradi AB, Oswald SE, Massner JA, Pruessmann KP, Robinson $\mathrm{BH}$, Schulin R. Magnetic resonance imaging methods to reveal the real-time distribution of nickel in porous media. Eur J Soil Sci 2008; 59(3): 476-85

[10] Oswald SE, Spiegel MA, Kinzelbach W. Three-dimensional saltwater-freshwater fingering in porous media: contrast agent MRI as basis for numerical simulations. Magn Reson Imaging 2007; 25(4): 537-40.

[11] Hoskins BC, Fevang L, Majors PD, Sharma MM, Georgiou G. Selective imaging of biofilms in porous media by NMR relaxation. J Magn Reson 1999; 139(1): 67-73.

[12] Seymour JD, Codd SL, Gjersing EL, Stewart PS. Magnetic resonance microscopy of biofilm structure and impact on transport in a capillary bioreactor. J Magn Reson 2004; 167(2): 322-27.

[13] Borgia GC, Fantazzini P, Mesini E. Water ${ }^{1} \mathrm{H}$ spin-lattice relaxation as a fingerprint of porous media. Magn Reson Imaging 1990; 8: 435-47

[14] Mansield P, Issa B. Studies of fluid transport in porous rocks by echo-planar MRI. Magn Reson Imag 1994; 12(2): 275-78.

[15] Muller M, Kooman S, Yaramanci U. Nuclear magnetic resonance (NMR) properties of unconsolidated sediments in field and laboratory. Near Surf Geophys 2005; 3(4): 275-85.

[16] Stallmach F, Vogt C, Kärger J, Helbig K, Jacobs F. Fractal geometry of surface areas of sand grains probed by pulsed field gradient NMR. Phys Rev Lett 2002; 88(10): 5505.

[17] Kenyon WE. Petrophysical principles of applications of NMR logging. The Log Analyst 1997; 38(2): 21-43.

[18] Bloembergen N, Purcel EM, Pound RV. Relaxation effects in nuclear magnetic resonance absorption. Phys Rev 1948; 73: 673-746.

[19] Solomon I. Relaxation processes in a system of two spins. Phys Rev 1955; 99: 559-65.

[20] Bloembergen N, Morgan LO. Proton relaxation times in paramagnetic solutions - Effects of electron spin relaxation. J Chem Phys 1961; 34: 842-50.

[21] Brownstein KR, Tarr CE. Importance of classical diffusion in NMR studies of water in biological cells. Phys Rev A 1979; 19(6): 2446-53.

[22] Kleinberg RL, Kenyon WE, Mitra PP. Mechanism of NMR relaxation of fluids in rocks. J Magn Reson Ser A 1994; 108: 206-14.

[23] Günther, H. NMR-Spektroskopie. Berlin: Wiley-VCH 1992. (German)

[24] Meiboom S, Gill D. Modified spin-echo method for measuring nuclear relaxation times. Rev Sci Instrum 1958; 29: 688-91.

[25] Carr HY, Purcell EM. Effects of diffusion on free precession in nuclear magnetic resonance experiments. Phys Rev 1954; 94: 63038.

[26] Bartacek J, Vergeldt FJ, Gerkema E, Jenicek P, Lens PNL, Van As $\mathrm{H}$. Magnetic resonance microscopy of iron transport in methanogenic granules. J Magn Reson 2009; 200(2): 303-12.

[27] Vogt C, Galvosas P, Klitzsch N, Stallmach F. Self-diffusion of pore fluids in consolidated sediments by PFG NMR. J Appl Geophys 2002; 50(4): 455-67.

[28] Jaeger F, Rudolph N, Lang F, Schaumann GE. Effects of soil solution's constituents on proton NMR relaxometry of soil samples. Soil Sci Soc Am J 2008; 72(6): 1694-707.

[29] Jaeger F, Grohmann E, Schaumann GE. ${ }^{1} \mathrm{H}$ NMR relaxometry in natural humous soil samples: Insights in microbial effects on relaxation time distributions. Plant Soil 2006; 280(1-2): 209-22.

(c) Mitreiter et al.; Licensee Bentham Open.

This is an open access article licensed under the terms of the Creative Commons Attribution Non-Commercial License (http://creativecommons.org/licenses/by-nc/3.0/) which permits unrestricted, non-commercial use, distribution and reproduction in any medium, provided the work is properly cited. 